\title{
Evolution of Average European Medicine Prices: Implications for the Methodology of External Price Referencing
}

\author{
Sabine $\operatorname{Vogler}^{1} \mathbb{C} \cdot$ Peter Schneider $^{1} \cdot$ Nina Zimmermann ${ }^{1}$
}

Published online: 5 February 2019

(c) The Author(s) 2019

\begin{abstract}
Background There are indications of staggered market entry of medicines in the national markets, with medicines being marketed first in countries with high prices. This study aimed to analyse the availability and evolution of medicine prices in the European Union (EU).

Methods This research was performed for an illustrative sample of five medicines (abiraterone, emtricitabine/rilpivirine/tenofovir disoproxil, fingolimod, linagliptin and sofosbuvir) in 27 EU Member States. Price data at 6, 12, 18, 36 and 60 months after marketing authorisation were retrieved from national administrative price databases and registers accessible through the Pharma Price Information service.

Results In the first year after marketing authorisation, price data for the selected medicines were only available in a small number of EU Member States-usually high-income countries. Availability increased over time. However, some countries, for instance Central and Eastern Europe, had price data available only several years after marketing authorisation. The average European price of the surveyed medicines decreased by at least $7.1 \%$ between 6 months and 3 years and at least $9.5 \%$ between 6 months and 5 years after marketing authorisation. Price data availability in lower-income countries at later stages, and price decreases in some countries, appear to be major reasons for the reductions in average prices.

Conclusions If policymakers aim to apply the pricing policy of external price referencing (i.e. price setting based on prices in other countries) for cost-containment purposes, they are recommended to undertake continuous price revisions over the years.
\end{abstract}

Electronic supplementary material The online version of this article (https://doi.org/10.1007/s41669-019-0120-9) contains supplementary material, which is available to authorized users.

Sabine Vogler sabine.vogler@goeg.at

1 WHO Collaborating Centre for Pharmaceutical Pricing and Reimbursement Policies, Pharmacoeconomics Department, Gesundheit Österreich GmbH (GÖG/Austrian Public Health Institute), Vienna, Austria

\section{Key Points for Decision Makers}

Across the Member States of the European Union, medicines are launched at different points in time, with delays of up to 3-5 years. Launch delays occur particularly in lower-income countries, countries with lower medicine prices, and small markets.

The study findings align with previous research that pharmaceutical companies have been applying a strategy to delay the launch of medicines in lower-income countries in light of the widespread use of the external price referencing (EPR) policy.

Since average European prices decrease over the years, regular revisions of the medicine prices in the reference countries, at longer intervals (such as 3 and 5 years), may help maximise the cost-containment potential of EPR. 


\section{Introduction}

Ensuring access to affordable medicines has been a major challenge globally [1]. In recent years, this has also become an issue for high-income countries, given the increasing marketing of medicines with high price tags $[2,3]$. While a debate about new pricing and funding policies for medicines and a change in the 'business model' of the development of medicines has been ongoing [4-9], the policy of external price referencing (EPR) is still a commonly used approach to set medicine prices in the Member States of the European Union (EU) and beyond [10-14]. EPR is defined as 'a practice of using the price(s) of a medicine in one or several countries in order to derive a benchmark or reference price for the purposes of setting or negotiating the price of the product in a given country [15].

Literature suggests several limitations of EPR, one of which relates to availability concerns. The EPR policy incentivises marketing authorisation holders to first launch medicines in countries with higher price levels, and to market them at a later point in time, or not at all, in countries that would have comparably lower prices for the same medicines. From a company's perspective, this is done with the aim of not reducing the average benchmark price that will be used by other EPR-applying countries [10, 16-20]. This impacts both higher-income and lowerresourced countries. While the latter are confronted with non-availability or delayed availability of new medicines, early-launch countries risk overpaying in case they do not monitor price developments in their reference countries and therefore miss adjusting their prices accordingly. Based on simulations of fictitious prices in current European EPR schemes, Vogler et al. [13] identified a higher frequency of price evaluations as one of the measures in the EPR methodology that would have high impact in terms of savings for public payers. If all EPR-applying countries re-evaluated their prices, based on the price in the reference countries, every 6 months after an initial price has been set, this would result in an average $6 \%$ price reduction in all 28 investigated EPR-applying countries after 10 years, compared with a situation in which countries continued performing EPR based on the same methodology as in 2015.

Against this backdrop, this research aimed to investigate, for a few selected medicines, the availability of price data in EU Member States and the evolution of EU average prices over time. Considering the availability of price data as a proxy for availability of the medicine in national markets, the study also aimed to identify options for improvement in the methodology design of the commonly used EPR policy.

\section{Methods}

The research was designed as an illustrative case study. Price data were surveyed for a small sample of medicines. Five medicines of different indications with known high budget impact for public payers [6, 21-24] were chosen: abiraterone (prostate cancer), emtricitabine/rilpivirine/tenofovir disoproxil (AIDS/HIV), fingolimod (multiple sclerosis), linagliptin (type 2 diabetes mellitus), and sofosbuvir (hepatitis C). All selected medicines had been granted a centralised marketing authorisation (i.e. that is valid in all EU Member States, Norway, Iceland and Liechtenstein [25]) in recent years (survey performed in March 2017). For each active ingredient, a specific pharmaceutical presentation representing a defined pharmaceutical form (e.g. tablet), strength and pack size was chosen for the analysis (Table 1).

Price data were analysed at different points in time: 6,12 , 18, 36 and 60 months after marketing authorisation. Data were retrieved from national administrative price databases and registers accessible through the Pharma Price Information (PPI) service [26] of the Austrian Public Health

Table 1 Selected medicines for the price analysis

\begin{tabular}{|c|c|c|c|c|c|c|}
\hline Active ingredient & Brand name & MAH & ATC code & $\begin{array}{l}\text { Pharmaceutical form, strength } \\
\text { and pack size }\end{array}$ & Indication & Date of MA \\
\hline Abiraterone & Zytiga $^{\circledR}$ & Janssen-Cilag & L02BX03 & 120 tablets, $250 \mathrm{mg}$ & Prostate cancer & $9 / 2011$ \\
\hline $\begin{array}{l}\text { Emtricitabine/rilpi- } \\
\text { virine/tenofovir } \\
\text { disoproxil }\end{array}$ & Eviplera $^{\circledR}$ & Gilead & J05AR08 & $\begin{array}{l}30 \mathrm{f} / \mathrm{c} \text { tablets, } \\
200 \mathrm{mg} / 25 \mathrm{mg} / 245 \mathrm{mg}\end{array}$ & AIDS/HIV & $11 / 2011$ \\
\hline Fingolimod & Gilenya $^{\circledR}$ & Novartis & L04AA27 & 28 capsules, $0.5 \mathrm{mg}$ & Multiple sclerosis & $3 / 2011$ \\
\hline Linagliptin & Trajenta ${ }^{\circledR}$ & Boehringer Ingelheim & A10BH05 & $\begin{array}{l}30 \mathrm{f} / \mathrm{c} \text { tablets, } 5 \mathrm{mg} \text { (alterna- } \\
\text { tive: } 28 \mathrm{f} / \mathrm{c} \text { tablets, } 5 \mathrm{mg} \text {, in } \\
\text { case of non-availability of } \\
\text { the selected medicines) }\end{array}$ & Type 2 diabetes mellitus & $8 / 2011$ \\
\hline Sofosbuvir & Sovaldi $^{\circledR}$ & Gilead & J05AX15 & 28 tablets, $400 \mathrm{mg}$ & Hepatitis C & $1 / 2014$ \\
\hline
\end{tabular}

ATC Anatomical, Therapeutic and Chemical, $M A$ marketing authorisation, $M A H$ marketing authorisation holder, $f / c$ film-coated 
Fig. 1 Price data availability of the selected medicines in the EU Member States. No data for sofosbuvir were available for the ' 60 months' period as the product only received marketing authorisation in January 2014 (data surveyed in March 2017). In Portugal, no price data for fingolimod were available from 12 months because, since 2012, no price data for medicines used in hospitals have been published in Portugal; however, the national price list informs that the product is marketed

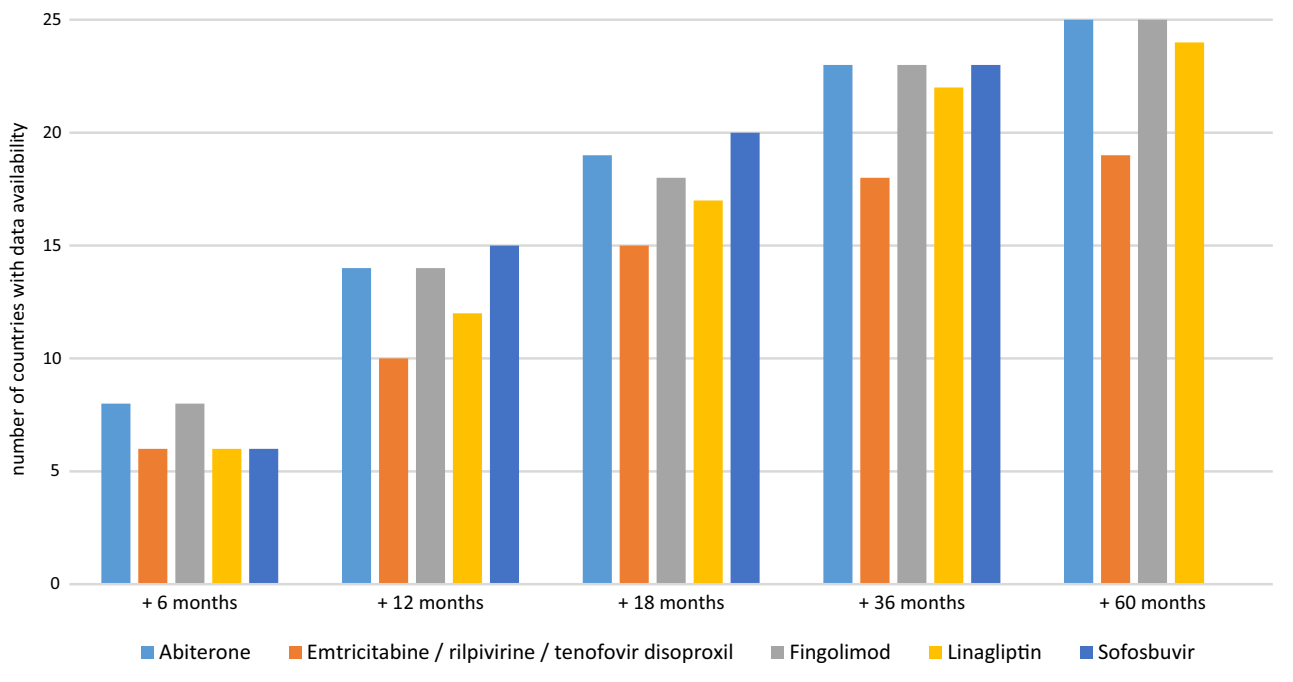

Institute, in addition to previous price data collections already included in the PPI system. ${ }^{1}$ The survey investigated ex-factory prices. For Cyprus, Denmark, Finland, The Netherlands, Sweden and the UK, where ex-factory prices are not officially available (government authorities set prices at the wholesale price level), the ex-factory prices were calculated through average wholesale margins as published in the Regulation on Procedural Rules for Calculation of the EU Average Price according to the General Social Insurance Law [27] in Austria, which were adjusted over time. Price information refers to official list prices (as published by the competent authorities) without consideration of discounts or claw-backs. While the survey initially aimed to cover all 28 EU Member States, no price data could be retrieved for Malta. Prices for England were taken as proxy for UK prices. In a few cases, ${ }^{2}$ price data were imputed. Prices per pack were compared. In the case of linagliptin, data for the defined pack size (30 film-coated tablets) were not available in a few countries, therefore the prices of the closest pack size (28 film-coated tablets) were considered and adjusted accordingly. For calculation of the average European prices, data from countries that did not have the Euro as its national currency at the surveyed points in time were

\footnotetext{
1 The Pharma Price Information (PPI) service offers medicine price information in all 28 EU Member States, as well as Norway and Switzerland, by providing access to national administrative databases. These databases have been established and maintained by competent authorities for pharmaceutical pricing and reimbursement (e.g. medicines agencies, Ministries of Health, social health insurance institutions) that are obliged, by the EU Transparency Directive (Council Directive 89/105/EEC), to publish price data of reimbursable medicines. These databases provide official published price data (list prices), without any discounts or rebates.

${ }^{2}$ For abiraterone, data related to 12 and 36 months for Portugal and 36 months for Sweden; for fingolimod, data related to 12 months for Finland.
}

converted into Euros. Conversion was based on the average monthly exchange rate of the previous month, as indicated by the European Central Bank. However, evolutions in prices were analysed based on data indicated in national currencies in order to avoid distortion related to exchange rate fluctuations.

\section{Results}

\subsection{Availability of Price Data}

For the majority of the EU Member States, no price data were available in the first year (6-8 countries had price data after 6 months, and 10-15 countries had price data after 12 months). After 18 and 36 months, data availability had considerably improved for the surveyed medicines (price data were available in 15-20 and 18-23 countries, respectively). Austria, Germany, Denmark and England always had price data available 6 months after marketing authorisation (with one exception for Germany, where linagliptin had not been marketed since no additional therapeutic benefit had been proven in the early benefit evaluation required by the Pharmaceuticals Market Reorganisation Act AMNOG [21]). For some of the medicines, Portugal, Finland and Slovenia had price data published 6 or 12 months after marketing authorisation. In Greece, Estonia, Lithuania and Latvia, as well as Bulgaria, Czech Republic and Slovakia, price data for some of the selected medicines were only available after 36 months, or later, or not at all (Fig. 1 and electronic supplementary material).

\subsection{Evolution of European Average Prices}

The price analysis showed that the European average prices (i.e. the average of the available prices of the medicines of 
Table 2 Change in the average European prices for the selected medicines at 6,12, 18, 36 and 60 months after marketing authorisation

\begin{tabular}{lllllll}
\hline Medicines & $6-12$ months (\%) & $\begin{array}{l}12-18 \text { months } \\
(\%)\end{array}$ & $\begin{array}{l}18-36 \text { months } \\
(\%)\end{array}$ & $\begin{array}{l}36-60 \text { months } \\
(\%)\end{array}$ & $\begin{array}{l}6-36 \text { months }(\%) \\
\text { 6-60 months (\%) }\end{array}$ \\
\hline Abiraterone & -3.8 & -2.4 & -4.1 & -4.3 & -10.0 & -13.9 \\
$\begin{array}{l}\text { Emtricitabine/rilpivirine/ } \\
\quad \text { tenofovir disoproxil }\end{array}$ & -5.2 & -2.0 & -5.9 & -4.2 & -12.5 & -16.2 \\
Fingolimod & -2.1 & -0.8 & -4.4 & -2.6 & -7.1 & -9.5 \\
Linagliptin & -1.8 & -4.9 & -3.3 & -1.9 & -9.7 & -11.4 \\
Sofosbuvir & -6.3 & -1.7 & -3.6 & - & -11.1 & - \\
\hline
\end{tabular}

The average European price was calculated based on the existing price data in the national markets. The change in price between 36 and 60 months could not be calculated for sofosbuvir as the product only received marketing authorisation in January 2014 and had thus not been on the market for 60 months at the time of the survey (March 2017)

the sample in the EU Member States) decreased over time (Table 2). On average, the European prices of the selected medicines were reduced by $7.1-12.5 \%$ between 6 months and 3 years, and by $9.5-16.2 \%$ between 6 months and 5 years after marketing authorisation. For all five surveyed medicines, the average European price was lower at all survey points compared with the previous observation point. The analysis of price evolutions (based on national currency units) showed that in some countries prices tended to remain at the same level in the shorter term (e.g. 1-2 years), while prices tended to decrease in the longer term (see electronic supplementary material). In a few cases, prices increased (e.g. emtricitabine/rilpivirine/tenofovir disoproxil in Finland, and linagliptin in Italy).

\section{Discussion}

\subsection{Findings in Light of Existing Pricing Policies}

The availability of price data is an indication for the market entry of medicines. Data from this study point to staggered marketing of medicines across countries (in the literature $[10,17-20]$, this approach has been described as a 'strategic launch' of marketing authorisation holders). If price data are considered as proxy for the availability of a medicine on the market, the findings imply that in some European countries patients have to wait for months and years after marketing authorisation before they can access the medicine (if affordable). Delayed accessibility of new medicines in some European countries has also been shown in other research [12, 19, 28-30].

A country's income level is one of the commonly provided explanations for staggered market entry. As such, medicines are first launched in countries with high-income (gross domestic product) per inhabitant in which solidarity-based funding schemes are able to afford higher prices. Delayed launches in lower-income and lower-priced countries are attributed to the widespread existence of the EPR policy as this staggered market entry allows companies to delay a reduction in prices $[10,17-20,28-31]$. In addition to a country's income and its medicine price levels, population size can also constitute a cause for availability limitations (delayed availability or non-availability) or affordability issues (i.e. smaller countries, due to their smaller markets, have been confronted with higher prices) $[20,28,29,32$, $33]$. Another factor is the extent and type of price regulation. From a marketing authorisation holder's perspective, within the (current) EU, Germany and England are considered to be the most attractive markets since they do not apply traditional price control measures [34] (in Germany, medicines can be brought on the market immediately after marketing authorisation, and prices are free during the first year [22]; and England's Pharmaceutical Price Regulation Scheme (PPRS) is designed as a profit control mechanism [35]). Further administrative reasons, including the marketing authorisation procedure or delays in assessments, may also play a role [29, 30, 36].

Overall, findings of this study suggest that medicines in countries with higher income and also higher medicine prices were launched earlier, compared with markets with lower income and medicine prices (the definition of price levels is based on the results of this analysis as well as further studies with a country basket of at least 15 of the 28 EU Member States [37-39] ${ }^{3}$ ). Germany, Austria and Denmark, high-income countries with high price levels, were among countries with early availability of price data and, assumingly, early availability of the medicines on the market, whereas price data were only available at later stages (in some cases even 3 or 5 years after marketing authorisation) in Greece and some Central and Eastern European countries. Research also showed delayed availability in smaller

\footnotetext{
3 A major limitation in existing literature is that most price comparisons are limited to a comparably small country basket (frequently five to ten countries), with a focus on large markets of high-income countries.
} 
markets, such as the Baltic countries (Estonia, Latvia and Lithuania) and Cyprus. At the same time, a few small markets in higher-income countries (Luxembourg, Slovenia) had earlier availability. Furthermore, the results are mixed with regard to Portugal (hit hard by the global financial crisis a few years ago) and Romania (among the lowest-income countries of the EU), which could have been expected to have major delayed availability. However, this was not the case, suggesting multifactorial reasons (e.g. Romania being a large market). It would require a larger basket of medicines to test whether or not this pattern prevails.

The decreases in the average European prices appear to result from both the inclusion of lower prices in some reference countries in which price data were available at a later point in time, and price reductions in other countries. This indicates that from a cost-containment perspective, EPRapplying countries could also benefit from continuous price revisions and, in particular, at later stages. There is room for improvement for countries that refrain from regular price evaluations or solely perform price revisions in a rather short interval after the launch of the medicine. According to a 2015 survey, 25 of 30 EPR-applying European countries do price monitoring, thereof 17 on a regular basis, whereas the remainder perform ad hoc price revisions. The duration of the intervals was reported to range between 3 months to 5 years [13].

In light of the limitations in access to and affordability of new medicines with high price tags, there have been discussions about the most appropriate pricing, as well as reimbursement and policies, both in research as well as at political levels [4-9, 40]. There is no 'one-size-fits-all' solution as there are different policies with regard to different types of medicines (e.g. on-patent vs. off-patent), price types (e.g. ex-factory prices vs. pharmacy retail prices) and policy objectives (i.e. early access to medicines, financial sustainability of the healthcare system, reward for innovation). The policy objectives depend on national priorities of policymakers, and are sometimes conflicting. As a result, policymakers may need to opt for a mix of different policy options [41, 42].

Policy options to ensure access to medicines also differ with regard to their feasibility and timelines. While some of them, for instance methodological changes in existing policies, are solutions in technical areas that can be implemented at short notice, others (e.g. collaborative approaches of countries to agree on principles of differential pricing or to do strategic procurement, or new funding mechanisms to simulate research and development) require high political commitment and can only be implemented in the long-term [43].

A pragmatic approach could be that, while policymakers work on developing new policy options in the longterm, they implement feasible, practical measures in the short-term. One of the policy changes that aim to ensure financial sustainability of healthcare systems is an optimisation of the methodological design for EPR; this implies regular revisions. The findings of this study provide (although for only a few medicines) an evidence base that the European average prices continue decreasing, even months and years after marketing authorisation. Since the frequency of price revisions under the EPR policy, and further methodological issues, are either determined in technical methodology papers or are regulated in a decree or a law, at national levels, such measures can be implemented rather swiftly in a country, without consultation of other countries. Nonetheless, it should be considered that EPR, including price revisions, is rather resource-intensive, in particular if the country basket is large. However, since most countries do not survey price data for EPR but ask the marketing authorisation holder to submit the price data of the reference countries [14], workload can be limited. In addition, improved collaboration between countries, such as through the price database Euripid, which is fed by pricing authorities of EU Member States [44], helps reduce the resources required for regular price revisions.

\subsection{Limitations}

This study has several limitations. First, the research was performed for a sample of a few medicines and is not comprehensive. There is room for further research to investigate whether or not a larger sample would lead to the same findings. Second, data had to be imputed in a few cases in which retrospective price data gathering was not possible and these data had not been included in the PPI system earlier. Third, the selected medicines are likely to be subject to discounts and further price-reducing arrangements, such as risk-sharing agreements and other managed entry agreements between the marketing authorisation holder and the public payer in several countries [3,45-50]. List prices were taken instead of actual discounted prices since the latter cannot be accessed given their confidential nature. Nonetheless, the list prices are relevant in this context as public authorities also use list prices of other countries when they apply EPR (solely the EPR legislation in Germany provides for the use of discounted prices [13]). ${ }^{4}$ Fourth, calculation of the average European prices was based on data expressed in Euros. In non-Euro countries, these data can be flawed due to exchange rate volatility. Finally, the availability of price data does not necessarily translate into actual patient access to medicines. A few countries indicate EPR-derived

\footnotetext{
${ }^{4}$ In Austria, since July 2017, price reductions based on mandatory manufacturer discounts (published data) in the reference countries have also been considered in the EPR-based price setting, but confidential discounts are not taken into account.
} 
national prices in their price databases, even for medicines that have not been marketed (and the price database does not indicate their availability). In addition, medicines may have been launched but are not yet available to patients at a certain point in time due to shortages [51] or because they are not affordable to patients in case of high out-of-pocket payments (e.g. as evidenced for cancer medicines [52]). In other countries, patients can have access to a medicine but its price is not necessarily publicly available (e.g. prices for hospital medicines have not been published in Portugal since 2012 [37]).

\section{Conclusions}

Ensuring affordable access to new high-priced medicines while not jeopardising the financial sustainability of the solidarity-based healthcare systems is a challenge for policymakers of high-income countries as well as lower- and middle-income countries.

As the commonly used EPR policy has major limitations, policymakers are encouraged to explore further pricing policies and alternative approaches beyond pricing in order to better achieve the above-mentioned policy objectives. However, in the meantime, if policymakers consider continuing using EPR as a tool to contain costs, they are advised to opt for a methodological design that is most appropriate for the intended purpose. The findings of this research add to previous studies $[12,13]$ that highlighted the potential of regular evaluations to bring down prices. Our study confirmed, at least for the sample of the selected medicines, that the availability of list prices in lower-priced countries was observed only years after marketing authorisation. This can be interpreted as an indication for 'strategic launches' of pharmaceutical companies. Thus, price revisions at longer intervals extended to some years can help reduce the list prices determined through EPR.

Acknowledgements The authors thank Margit Gombocz, Klaus Kellner, and Friederike Windisch of the PPI service of the Austrian Public Health Institute for their support in the collection of the national medicine price data.

Author Contributions This article was conceived by SV. In consultation with SV and NZ, PS developed and adjusted the methodology for the collection of the price data. Together with further members of the PPI service affiliated to the Austrian Public Health Institute who are listed in the Acknowledgements section, PS and NZ contributed to the collection of the primary price data. NZ and SV took the lead in the analysis of the data. SV wrote the first draft of the paper and revised it following the reviews of PS and NZ. All authors read and approved the final version submitted for publication.

Data Availability Statement Data generated and analysed during this study are included in the electronic supplementary material.

\section{Compliance with Ethical Standards}

Funding The PPI service established at the Austrian Public Health Institute enables the authors and their contributors listed in the Acknowledgements section to access national medicine price databases. The support of the Austrian Federal Ministry of Labour, Social Affairs, and Health and Consumer Protection to maintain the PPI service is gratefully acknowledged. No specific funding was received for the preparation of this article.

Conflict of interest Sabine Vogler, Peter Schneider, and Nina Zimmermann declare that they have no conflicts of interest.

Open Access This article is distributed under the terms of the Creative Commons Attribution-NonCommercial 4.0 International License (http://creativecommons.org/licenses/by-nc/4.0/), which permits any noncommercial use, distribution, and reproduction in any medium, provided you give appropriate credit to the original author(s) and the source, provide a link to the Creative Commons license, and indicate if changes were made.

\section{References}

1. WHO. The World Medicines Situation. Access to Essential Medicines as Path of the Right to Health. Geneva: WHO; 2011. Available at: http://apps.who.int/medicinedocs/documents/s18772en/ s18772en.pdf. Accessed 1 Dec 2018.

2. Vogler S, Paris V, Ferrario A, Wirtz VJ, de Joncheere K, Schneider $\mathrm{P}$, et al. How can pricing and reimbursement policies improve affordable access to medicines? Lessons learned from European countries. Appl Health Econ Health Policy. 2017;15(3):1-15.

3. Vogler S, Paterson KR. Can price transparency contribute to more affordable patient access to medicines? PharmacoEcon Open. 2017;1(3):145-7.

4. Ministry of Health Welfare and Sport. Summary of medicines plan. The Hague; 2016. Available at: http://english.eu2016.nl/ binaries/eu2016-en/documents/publications/2016/03/1/summa ry-of-medicins/summary-of-medicines-plan.pdf. Accessed 14 May 2016.

5. WHO. Fair Pricing Forum. 2017 Meeting Report. Geneva: WHO; 2017. Available at: http://www.who.int/medicines/acces s/fair_pricing/FairPricingForum2017MeetingReport.pdf?ua=1. Accessed 3 Aug 2018.

6. WHO Regional Office for Europe. Access to new medicines in Europe: technical review of policy initiatives and opportunities for collaboration and research. Copenhagen: WHO; 2015.

7. OECD. New Health technologies: managing access, value and sustainability. Paris: OECD Publishing; 2017.

8. OECD. Pharmaceutical innovation and access to medicines, OECD Health Policy Studies. Paris: OECD Publishing; 2018.

9. Parkinson B, Sermet C, Clement F, Crausaz S, Godman B, Garner $\mathrm{S}$, et al. Disinvestment and value-based purchasing strategies for pharmaceuticals: an international review. Pharmacoeconomics. 2015;33(9):905-24.

10. Espin J, Rovira J, de Labry AO. Working paper 1: external price referencing - review series on pharmaceutical pricing policies and interventions. Geneva: World Health Organization and Health Action International; 2011.

11. Leopold C, Vogler S, Mantel-Teeuwisse AK, de Joncheere $\mathrm{K}$, Leufkens HG, Laing R. Differences in external price 
referencing in Europe-a descriptive overview. Health Policy. 2012;104(1):50-60.

12. Toumi M, Rémuzat C, Vataire A-L, Urbinati D. External reference pricing of medicinal products: simulation-based considerations for cross-country coordination. Final Report. Brussels: European Commission; 2014.

13. Vogler S, Lepuschütz L, Schneider P, Stühlinger V. Study on enhanced cross-country coordination in the area of pharmaceutical product pricing. Luxembourg: Gesundheit Österreich Forschungs- und Planungs GmbH; Publications Office of the European Commission; 2016.

14. Schneider P, Vogler S. Practice of external price referencing (EPR). In: Vogler S, editor. Medicine price surveys, analyses and comparisons. London: Elsevier; 2019.

15. WHO Collaborating Centre for Pharmaceutical Pricing and Reimbursement Policies. Glossary of pharmaceutical terms. Update 2016. Vienna: 2016. Available from: http://whocc.goeg.at/Liter aturliste/Dokumente/MethodologyTemplate/Glossary_Updat e2016_final.pdf. Accessed 5 Jan 2018.

16. Gandjour A. Reference pricing and price negotiations for innovative new drugs. PharmacoEconomics. 2013;31(1):11-4.

17. OECD. Pharmaceutical pricing policies in a global market. Paris: OECD; 2008.

18. Danzon PM, Wang YR, Wang L. The impact of price regulation on the launch delay of new drugs: evidence from twenty-five major markets in the 1990s. Health Econ. 2005;14(3):269-92.

19. Kyle MK. Pharmaceutical price controls and entry strategies. Rev Econ Stat. 2007;89(1):88-99.

20. Kaló Z, Alabbadi I, Al Ahdab OG, Alowayesh M, Elmahdawy M, Al-Saggabi AH, et al. Implications of external price referencing of pharmaceuticals in Middle East countries. Expert Rev Pharmacoecon Outcomes Res. 2015;15(6):993-8.

21. Schwabe U, Paffrath D. Arzneiverordnungs Report 2014: Aktuelle Daten, Kosten, Trends und Kommentare. Berlin: Springer; 2014.

22. Schwabe U, Paffrath D, Ludwig W-D, Klauber J. Arzneiverordnungs Report 2017. Berlin: Springer; 2017.

23. Iyengar S, Tay-Teo K, Vogler S, Beyer P, Wiktor S, de Joncheere $\mathrm{K}$, et al. Prices, costs, and affordability of new medicines for hepatitis $\mathrm{C}$ in 30 countries: an economic analysis. PLoS Med. 2016;13(5):e1002032.

24. Vogler S, Schneider P, Zimmermann N. Price comparison of highcost medicines 2015 [in German]. Vienna: Gesundheit Österreich $\mathrm{GmbH} ; 2016$.

25. EMA. Website of the European Medicines Agency London 2017. Available at: https://www.ema.europa.eu/en/human-regulatory/ marketing-authorisation. Accessed 30 Jan 2019.

26. Vogler S, Schneider P. Medicine price data sources. In: Vogler S, editor. Medicine price surveys, analyses and comparisons. London: Elsevier; 2019.

27. Bundesministerium für Gesundheit und Frauen. Regulation on Procedural Rules for Calculation of the EU average price according to $\S 351 \mathrm{c} 6$ and 9a General Social Insurance Law. Bundesministerium für Gesundheit und Frauen; 2017.

28. Economics Copenhagen. Study on the economic impact of supplementary protection certificates, pharmaceutical incentives and rewards in Europe. Brussels: Commissioned by the European Commission, GROW Directorate-General; 2018.

29. Insight Matrix. Study on the availability of medicinal products for human use. Luxembourg: Commissioned by the European Commission, Executive Agency for Health and Consumers; 2012.

30. Economics Europe. External price referencing. London: Europe Economics; 2013.

31. Rémuzat C, Urbinati D, Mzoughi O, El Hammi E, Belgaied W, Toumi M. Overview of external reference pricing systems in Europe. J Mark Access Health Policy. 2015. https://doi. org/10.3402/jmahp.v3.27675.
32. Leopold C, Rovira J, Habl C. Generics in small markets or for low volume medicines European Union. Vienna: EMINet; 2010.

33. de Labry Lima AO, Espín Balbino J, Rovira Forns J. Literature review on entry of medicines in European small markets. Pharm Policy Law. 2012;14(2):187-93.

34. Persson U, Jönsson B. The end of the international reference pricing system? Appl Health Econ Health Policy. 2016;14(1):1-8.

35. UK Department of Health. The Pharmaceutical Price Regulation Scheme 2014. Guidance. UK Department of Health; 2013.

36. Ferrario A, Reinap M, Pedersen HB, Kanavos P. Availability of medicines in Estonia: an analysis of existing barriers and options to address them. Copenhagen: WHO, Regional Office for Europe; 2016.

37. Vogler S, Vitry A, Babar ZUD. Cancer drugs in 16 European countries, Australia, and New Zealand: a cross-country price comparison study. Lancet Oncol. 2016;17(1):39-47.

38. van Harten WH, Wind A, de Paoli P, Saghatchian M, Oberst S. Actual costs of cancer drugs in 15 European countries. Lancet Oncol. 2016;17(1):18-20.

39. Vogler S, Zimmermann N, Babar ZUD. Price comparison of highcost originator medicines in European countries. Expert Rev Pharmacoecon Outcomes Res. 2017;17(2):221-30.

40. Wettstein DJ, Boes S. Effectiveness of national pricing policies for patent-protected pharmaceuticals in the OECD: a systematic literature review. Appl Health Econ Health Policy. https://doi. org/10.1007/s40258-018-0437-z (epub 27 Oct 2018).

41. Vogler S, Haasis MA, Dedet G, Lam J, Bak Pedersen H. Medicines reimbursement policiies in Europe. Copenhagen: World Health Organization; 2018.

42. Habl C, Schneider P, Németh G, Šebesta R. Euripid guidance document on external reference pricing (ERP), version 8.1. 2018. https://ppri.goeg.at/sites/ppri.goeg.at/files/inline-files/EURIP ID_GuidanceDocument_V8.1_310718_5_0.pdf. Accessed 30 Jan 2019.

43. Vogler S, Paris V, Panteli D. Ensuring access to medicines: How to redesign pricing, reimbursement and procurement? Policy Brief 30. Copenhagen: World Health Organization; 2018.

44. Euripid Collaboration. Euripid 2018. Available at: https://eurip id.eu/aboutus. Accessed 3 Dec 2018.

45. Ferrario A, Arāja D, Bochenek T, Čatić T, Dankó D, Dimitrova M, et al. The implementation of managed entry agreements in Central and Eastern Europe: findings and implications. Pharmacoeconomics. 2017;35(12):1271-85.

46. Towse A, Garrison LP. Can't get no satisfaction? Will pay for performance help? Pharmacoeconomics. 2010;28(2):93-102.

47. Pauwels K, Huys I, Vogler S, Casteels M, Simoens S. Managed entry agreements for oncology drugs: lessons from the European experience to inform the future. Front Pharmacol. 2017;8:171.

48. Vogler S, Zimmermann N, Habl C, Piessnegger J, Bucsics A. Discounts and rebates granted to public payers for medicines in European countries. South Med Rev. 2012;5(1):38-46.

49. Mattingly TJ, Levy JF, Slejko JF, Onwudiwe NC, Perfetto EM. Estimating drug costs: how do manufacturer net prices compare with other common US price references? PharmacoEconomics. 2018;36(9):1093-9.

50. Garattini L, Curto A. Performance-based agreements in italy: 'trendy outcomes' or mere illusions? Pharmacoeconomics. 2016;34(10):967-9.

51. Gray A, Manasse HR Jr. Shortages of medicines: a complex global challenge. Bull World Health Organ. 2012;90(3):158-158A.

52. Cherny N, Sullivan R, Torode J, Saar M, Eniu A. ESMO European Consortium Study on the availability, out-of-pocket costs and accessibility of antineoplastic medicines in Europe. Ann Oncol. 2016;27(8):1423-43. 